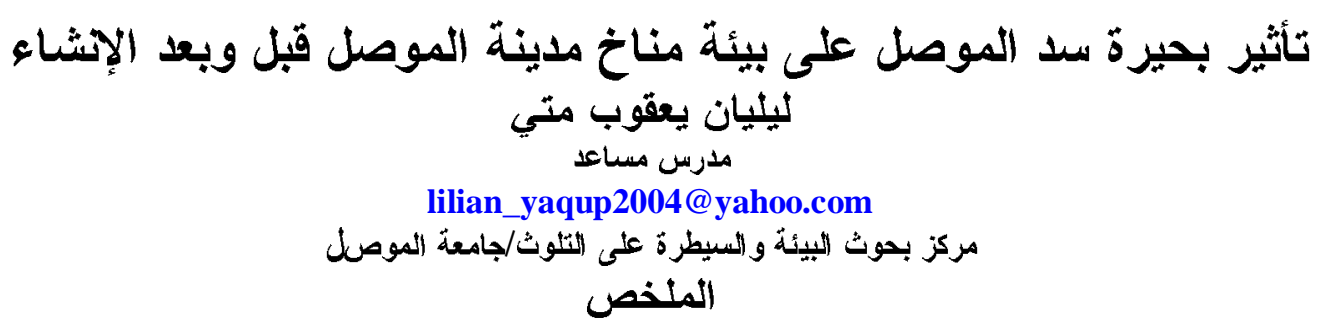

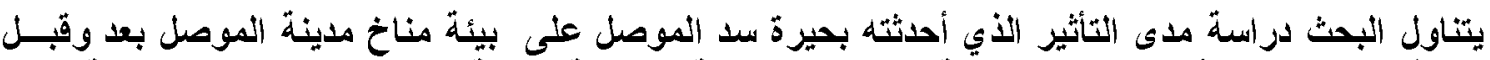

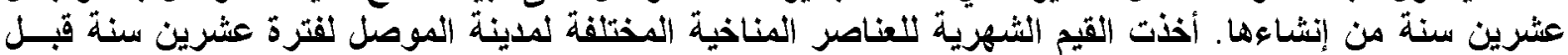

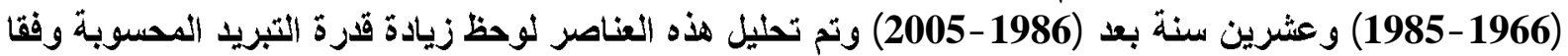

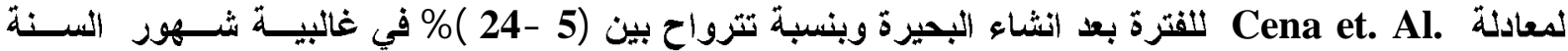

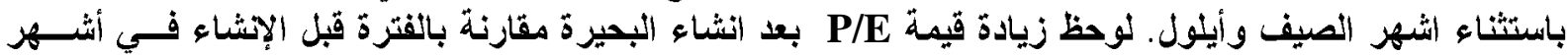

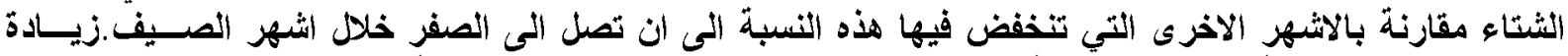

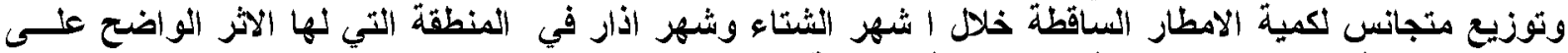

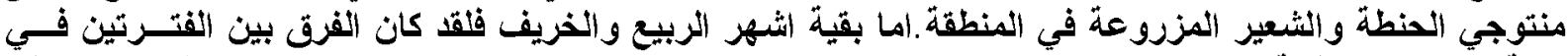

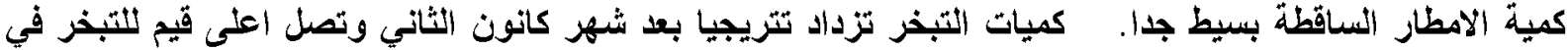

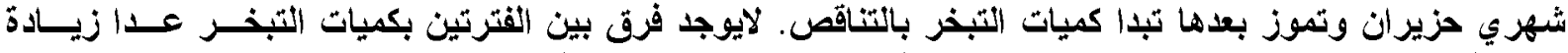

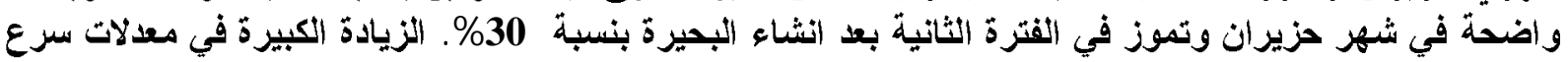

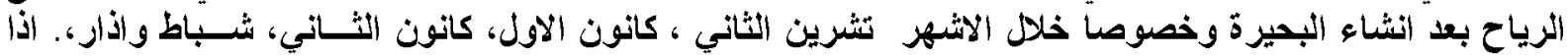

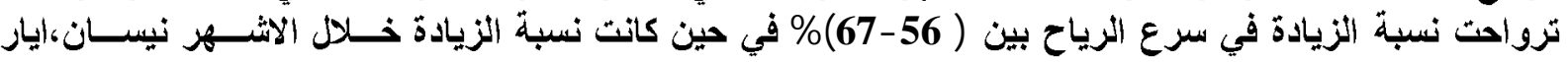

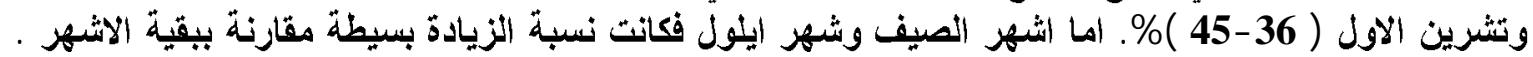

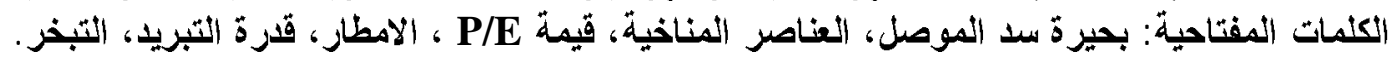

\title{
Affect Mosul Dam Lake of climates in Mousl city before and after construct \\ Lelian Yaqoob Matti
}

\section{Abstract}

The research studies the impact of Mosul Dam Lake on the climate of Mosul city, and comparison of the climate before and after the lake establishment. Monthly values of various climatic elements were analyzed for a period of twenty years before the establishment (1966-1985) and twenty years after it(1986-2005). The analysis shows that there is an increase in cooling capacity calculated, according to the equation Cena et. al. after the establishment and at a rate ranging between $(5-24) \%$ in most months but not in summer months and September. It is found that the value of $P / E$ is also increased in this period compared with that before the establishment. this value increases in winter months compared with the other months with low this percentage to reach zero during the summer months. In addition, there is an increase in the quantity of rainfall during winter months and March which highly affects wheat and barley growth in the region, whereas the comparison between the two periods concerning the amount of rainfall in spring and Autumn months is very simple. Quantity of evaporation increases gradually after January and reaches its highest values in June and July then it starts decreasing.. There is no difference between the two periods except for quantities of evaporation a where a noticeable increase in June and July by $30 \%$ in the second period after the establishment. Furthermore, a significant increase in wind acceleration is also observed after the establishment especially during November, December, January, February and March,. this increase is ranged between (56-67\%) while during April, May and October, it is ranged (36-45)\%.the summer and September, the rate of increase is minor compared to other months. 


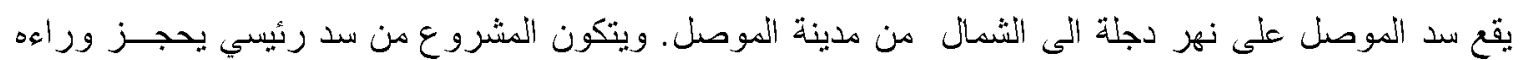

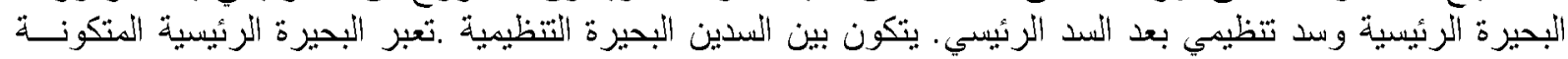

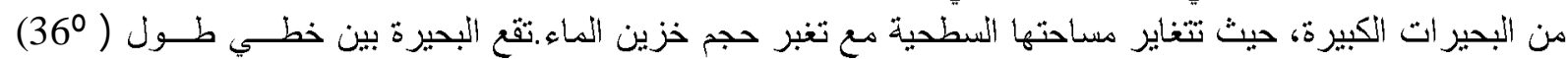
30N,370

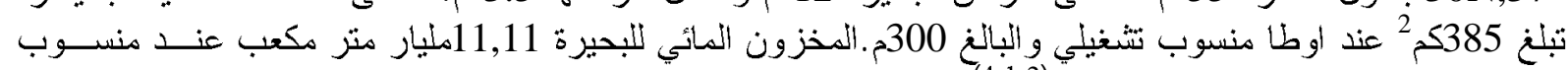

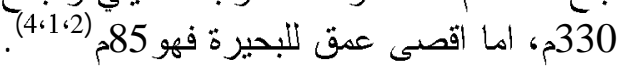

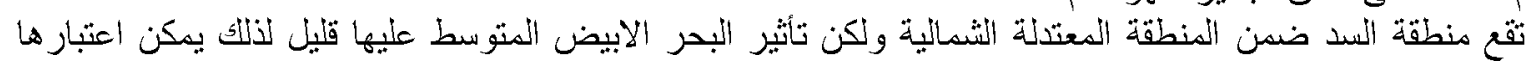

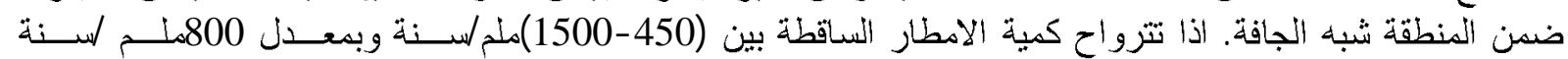

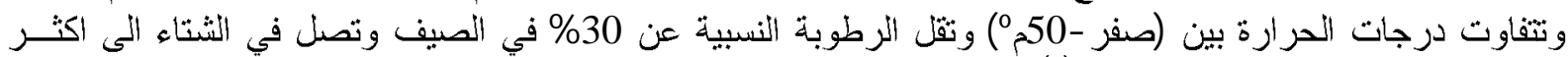

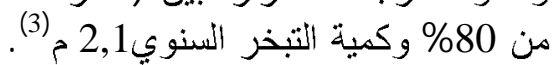
تعتبر منطقة الموصل منطقة معتدلة دافئة وهي عاصمة محافظة نينوي العر اقية وييلغ ارتفاعها 223م فوق مستوى

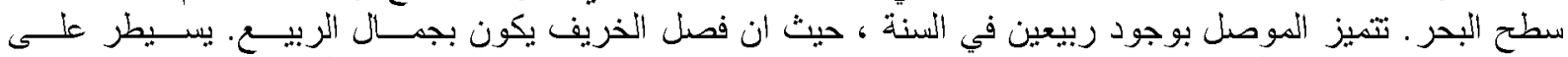

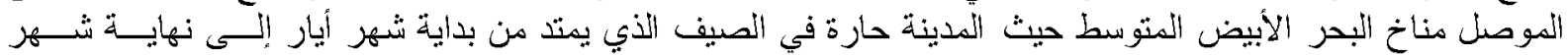

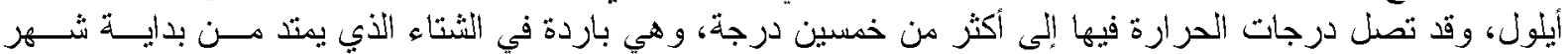

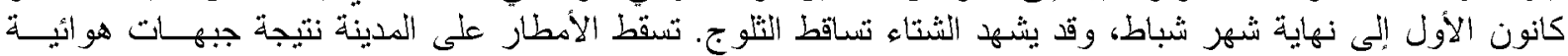

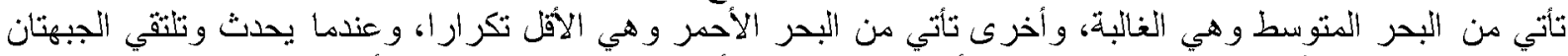

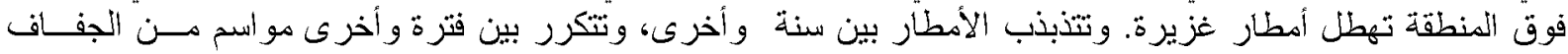

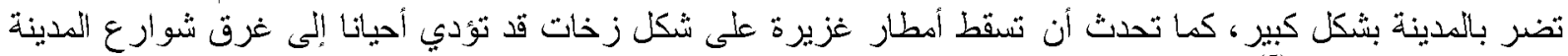

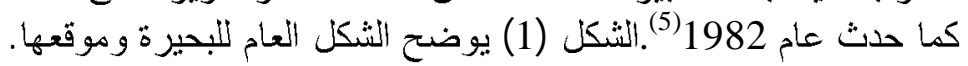
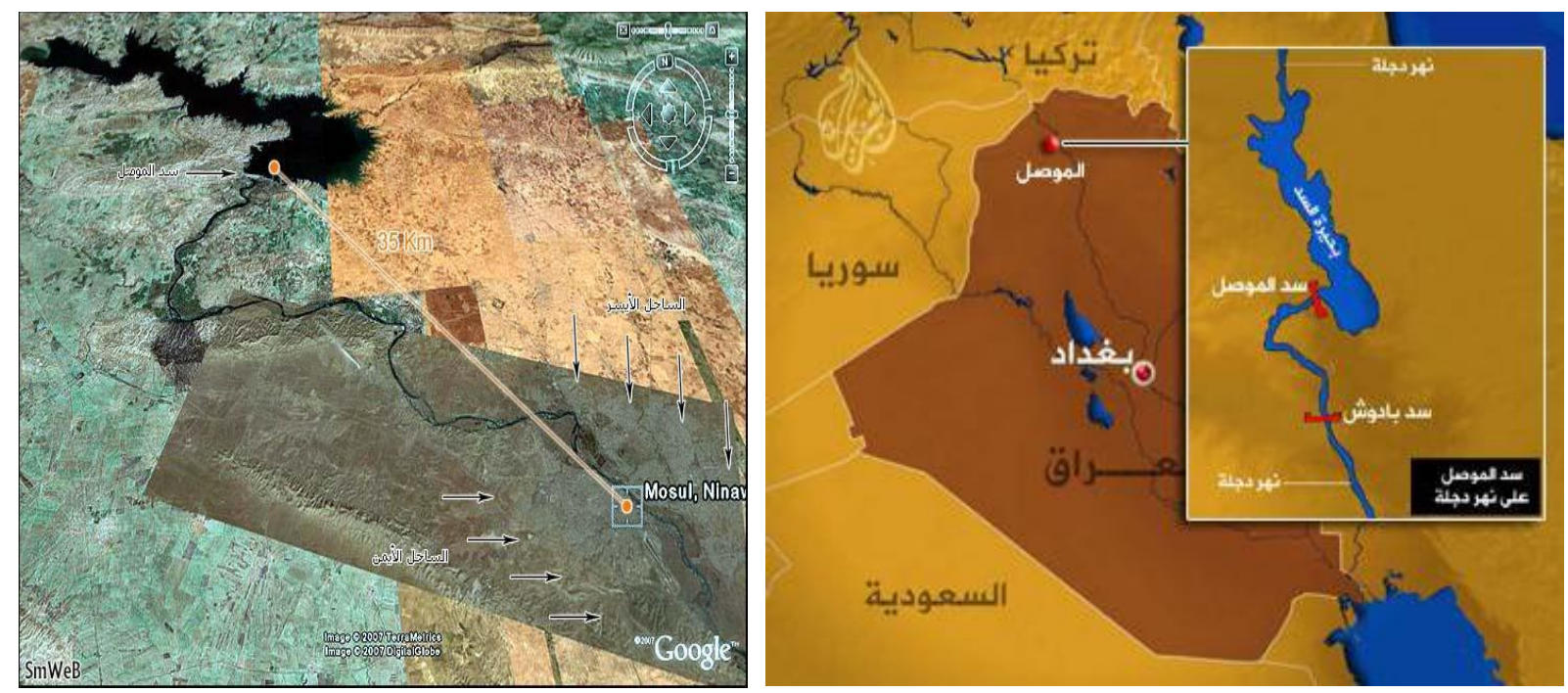

$$
\text { الشكل (1) يوضح الشكل العام للبحيرة وموقعها. }
$$

\section{الارزاسـات السـابقة}

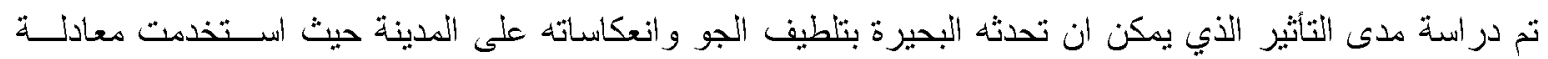

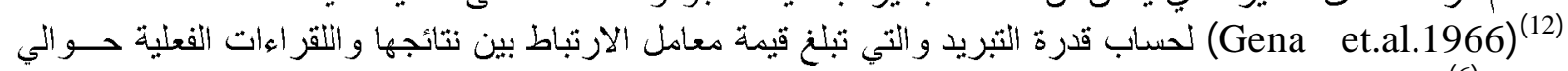

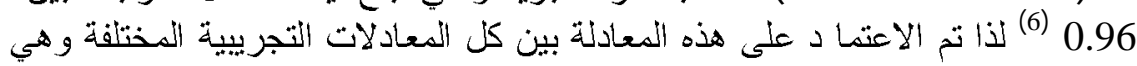

$\mathrm{H}=(0.412+0.087 \mathrm{v})(36.5-\mathrm{t})$ 


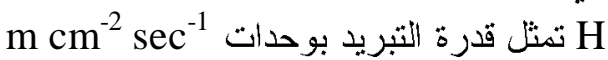

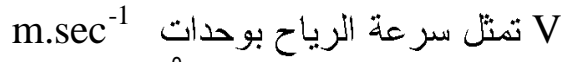

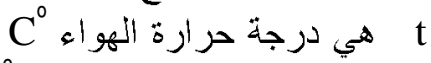

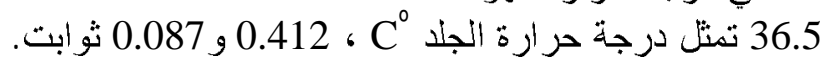

لقد وضع Landsberg جدو لا يصف الاحساس البشري تبعأ لفئات مختلفة من قدرة التبريد جدول (1). جدول (1) يصف الاحساس البشري تبعاً لفئات مختلفة من قدرة التبريد(13)

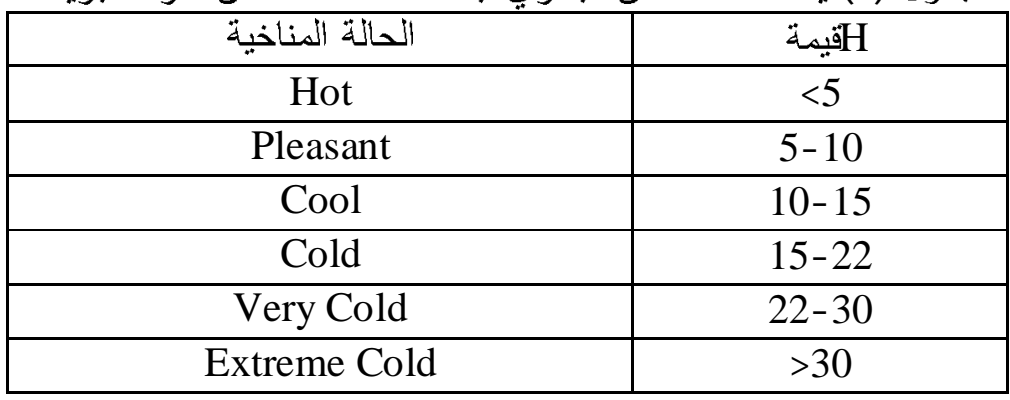

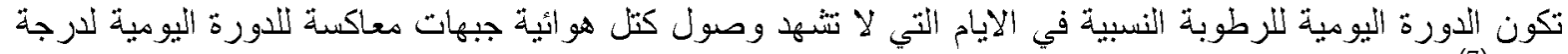

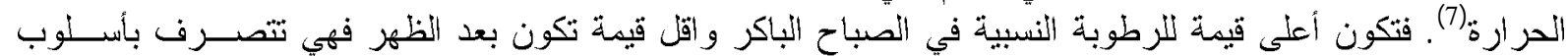

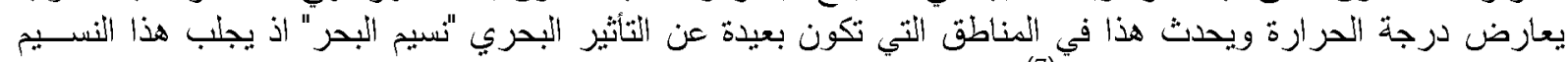

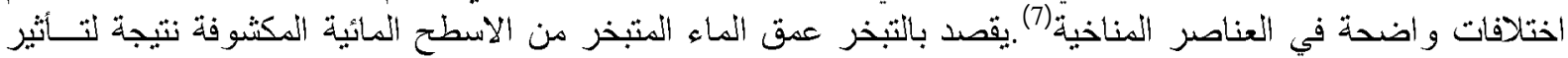
الظروف المناخية من الحرارة في الترياح و غير ها.

يعتبر المطر هن اهم مظاهر التساقط و هو عبارة عن سقوط الماء على شكل قطرات سائًّ يزيد قطر ها غالباعن 0.5

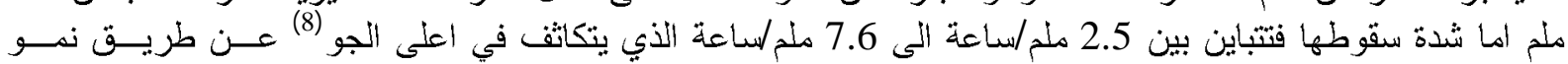

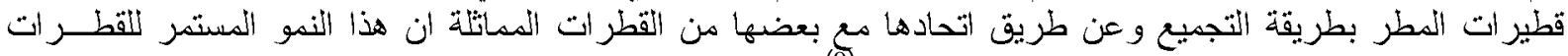

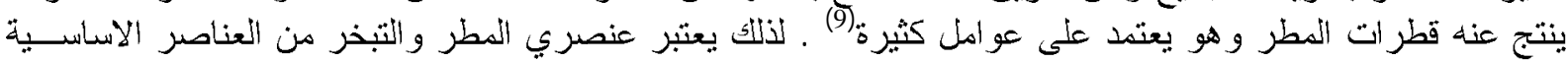

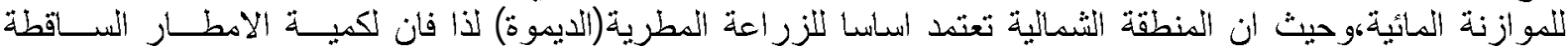
وتوزيعها الهمية بالغة.

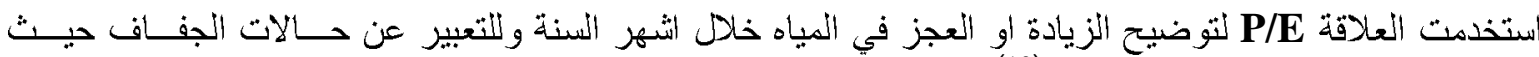

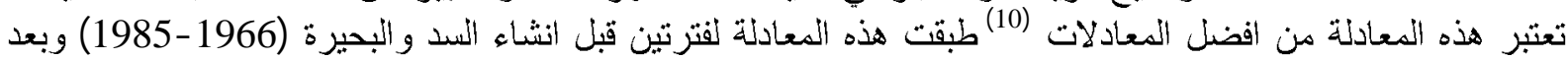

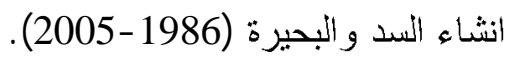
تم اجر اء تقييم شامل لمعظم العناصر المناخية لمعرفة مدى تأثير انشاء البحيرة على مناخ المنطقة.

\section{طريقة العمل}

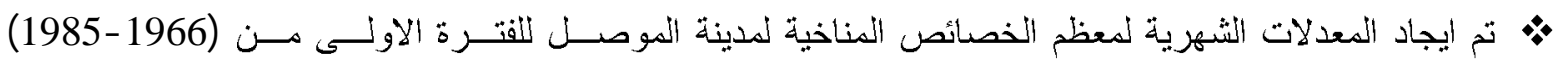

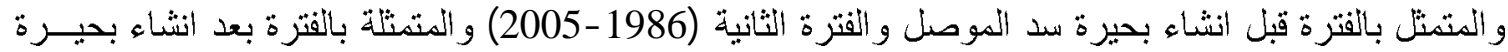

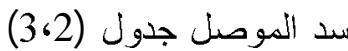

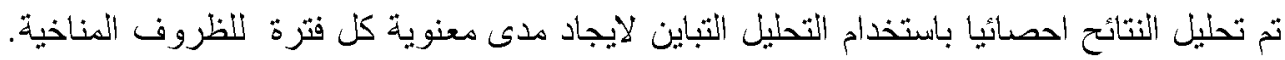
تم استخدام اختبار دنكن للمقارنة بين الخصائص المناين الفاخية خلادل الشهر السنة.

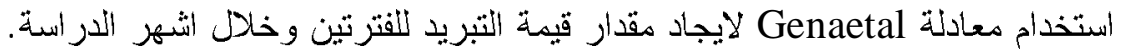
استخدام العلاقة P/E للتعبير عن حالات الجفاف خلال الفتزتين والتين واتشهر الدراسة. 
جدول (2) يوضح المعدلات الثهرية للعناصر المناخية لمدينة الموصل للفترة (1966 -1985 ) قبل انشاء بحيرة سد الموصل

(اعتمادا على سجلات الميئة العامة للانو اء الجوية العر اقبة)

\begin{tabular}{|c|c|c|c|c|c|c|c|c|c|c|c|c|}
\hline كانون & الثثانين & تلثترين & ايلول & ابب & تموز & حزيران & ايار & نيسان & اذذار & شباط & كانثين & خصائص الأشهر \\
\hline 58 & 56 & 12.3 & 1.2 & $\mathbf{0}$ & $\mathbf{0}$ & $\mathbf{0}$ & 13.2 & 41 & 62 & 61.9 & 60 & (الامطار \\
\hline 25 & 60 & 141 & 244 & 384 & 279 & 235 & 229 & 131 & 87 & 46 & 27 & التبخز (mm) \\
\hline 0.41 & 0.39 & 0.61 & 0.99 & 1.33 & 1.62 & 1.42 & 1.3 & 0.91 & 0.72 & $\begin{array}{cll}0.7 \\
\end{array}$ & 0.51 & $\begin{array}{c}\text { سرعة الرياح) } \\
\text { (m/s) }\end{array}$ \\
\hline 82 & 67 & 45 & 30 & 26 & 23 & 28 & 43 & 67 & 70 & 76 & 81 & الرطوبة" النسبيةه\%" \\
\hline 12 & 19.5 & 28.2 & 37 & 41.3 & 43.5 & 38 & 31.5 & 25 & 18 & 13 & 11 & 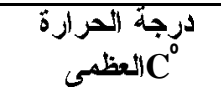 \\
\hline 2.9 & 6.7 & 12.1 & 17 & 21.8 & 23 & 18.5 & 15 & 10.7 & 5.3 & 2.6 & 1.3 & 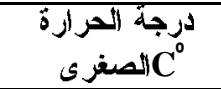 \\
\hline 7.45 & 13.1 & 20.15 & 27 & 31.55 & $\begin{array}{c}33.2 \\
5\end{array}$ & 28.25 & $\begin{array}{c}23.2 \\
5\end{array}$ & 17.85 & $\begin{array}{c}11.6 \\
5\end{array}$ & 7.8 & 6.15 & معال لدرجة \\
\hline 6.1 & 10 & 13.7 & 17 & 19.3 & 19.5 & 18.9 & 16.8 & 13 & 9.3 & 6.1 & 5.3 & 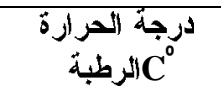 \\
\hline 171 & 218 & 312 & 443 & 528 & 579 & 601 & 512 & 415 & 331 & 253 & 175 & الاشعاع الشمسي \\
\hline 1020 & 1015 & 1013 & $\begin{array}{c}100 \\
3\end{array}$ & 1001 & $\begin{array}{c}100 \\
0\end{array}$ & 999.8 & $\begin{array}{c}100 \\
8\end{array}$ & 1010 & $\begin{array}{c}101 \\
5\end{array}$ & $\begin{array}{c}102 \\
5\end{array}$ & 1021 & الضغط ألجوي \\
\hline
\end{tabular}

جدول (3) يوضح المعدلات الثهرية للعناصر المناخية لمدينة الموصل للفترة (1986 -2005 ) بعد انثاء بحيرة سد الموصل المدينة المرد

(اعتمادا على سجلات الهيئة العامة للانو اء الجوية العر اقية)

\begin{tabular}{|c|c|c|c|c|c|c|c|c|c|c|c|c|}
\hline كانون & تالثرانين & تشثرين & ايلول & اب & تموز & حزيران & ايار & نيسان & أذار & شباط & كانون & خصائص الاشهر \\
\hline 70 & 58 & 17.1 & 0 & 0 & 0 & 3.1 & 20.3 & 44 & 79.5 & 71 & 62 & (الامطار )(mm) \\
\hline 27 & 60 & 143 & 250 & 339 & 402 & 335 & 235 & 132 & 90 & 43 & 27 & (التبخر)(mm) \\
\hline 1.2 & 0.99 & 0.96 & 1.18 & 1.66 & 1.8 & 1.8 & 2.1 & 1.65 & 1.7 & 1.6 & 1.2 & سرعة الرياح) \\
\hline 85 & 63 & $\overline{50}$ & 32 & 30 & 28 & 30 & 48 & 64 & 70 & 75 & 80 & الأنسبيةهُهة \\
\hline 12.1 & 19.8 & 28 & 39 & 41.3 & 44.5 & 40.2 & 32 & 27 & 19 & 15 & 11.5 & 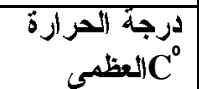 \\
\hline 3.1 & 7 & 12.6 & 17.5 & 22.9 & 23.2 & 19 & 16 & 10.9 & 5.8 & 2.9 & 1.5 & 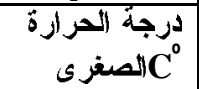 \\
\hline 7.6 & 13.4 & 20.3 & 28.25 & 32.1 & 33.85 & 29.6 & 24 & 18.95 & 12.4 & 8.95 & 6.5 & 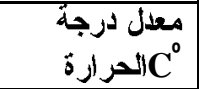 \\
\hline 5.9 & 10 & 17 & 16.5 & 19.8 & 19.5 & 18.4 & 18 & 12.9 & 8.9 & 6.3 & 5 & 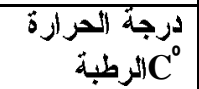 \\
\hline 168 & 225 & 336 & 489 & 560 & 600 & 620 & 515 & 458 & 365 & 256 & 182.5 & 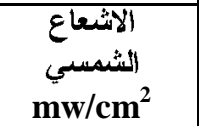 \\
\hline 1025 & 1020 & 1019 & 1007 & 1001 & 998 & 1001 & 1012 & 1015 & 1018 & 1029 & 1023 & الضغط الجوي \\
\hline
\end{tabular}




\section{النتائج و المناقتثة}

1

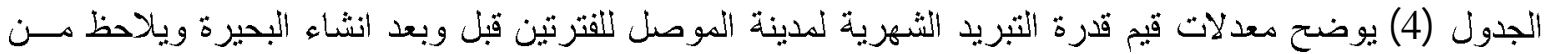

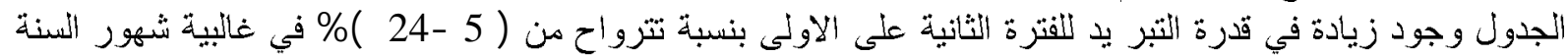

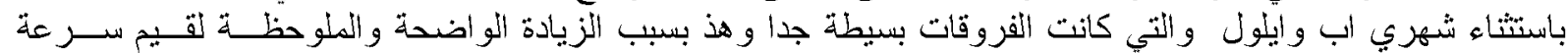

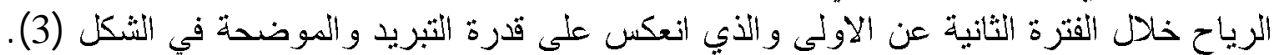

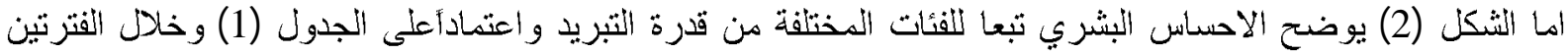

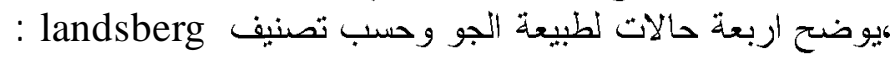
الأونى باردة و المتفلة كانون الثاني وشباط للفترة الثانية بعد انثاء البحيرة

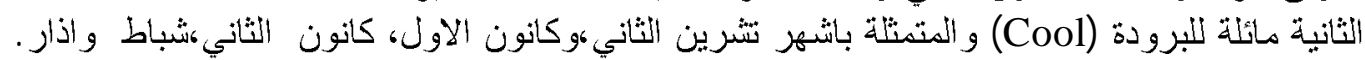

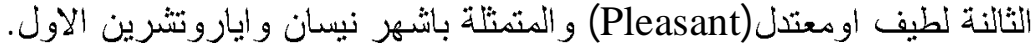

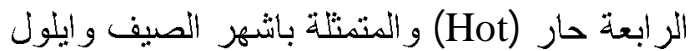
وهذا بشكل عام تمثل السمات العامة الملاحظة على طبيعية جومدينة الموصل.

\begin{tabular}{|c|c|c|c|c|c|c|c|c|c|c|c|c|}
\hline كانون & تالثناني & تلثرين & ايلول & اب & تموز & حزيران & ايار & نيسان & أذار & شباط & الثانون & الآشهر \\
\hline 13.00 & 10.43 & 7.60 & 4.48 & 2.61 & 1.244 & 3.88 & 6.96 & 9.16 & 11.79 & 13.57 & 13.85 & ثلثرة التبريد من 1966 - للفرة 1985 \\
\hline 14.92 & 11.51 & 8.03 & 4.25 & 2.49 & 1.51 & 3.92 & 7.43 & 9.749 & 13.49 & 15.18 & 18.074 & 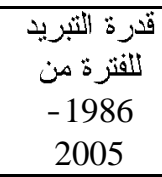 \\
\hline 12.87 & 9.38 & 5.35 & 5.41- & 4.82 & 17.62 & 1.02 & 6.33 & 6 & 12.6 & 10.6 & 23.37 & الفترة الألفانين \\
\hline
\end{tabular}

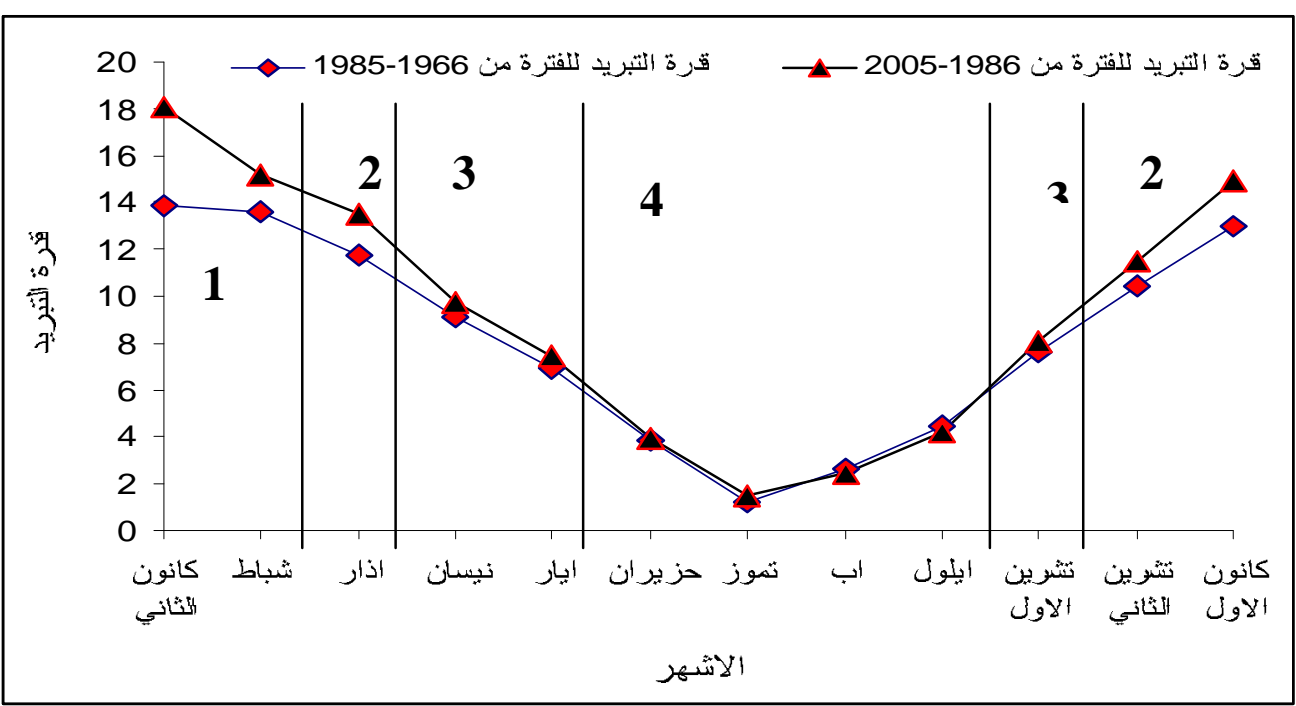

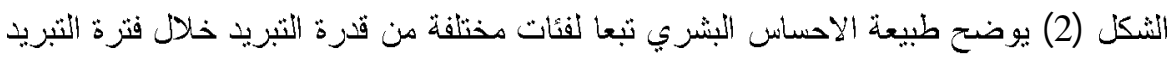

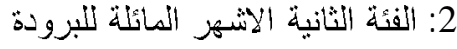

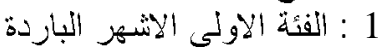

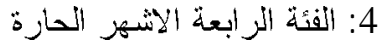

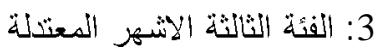




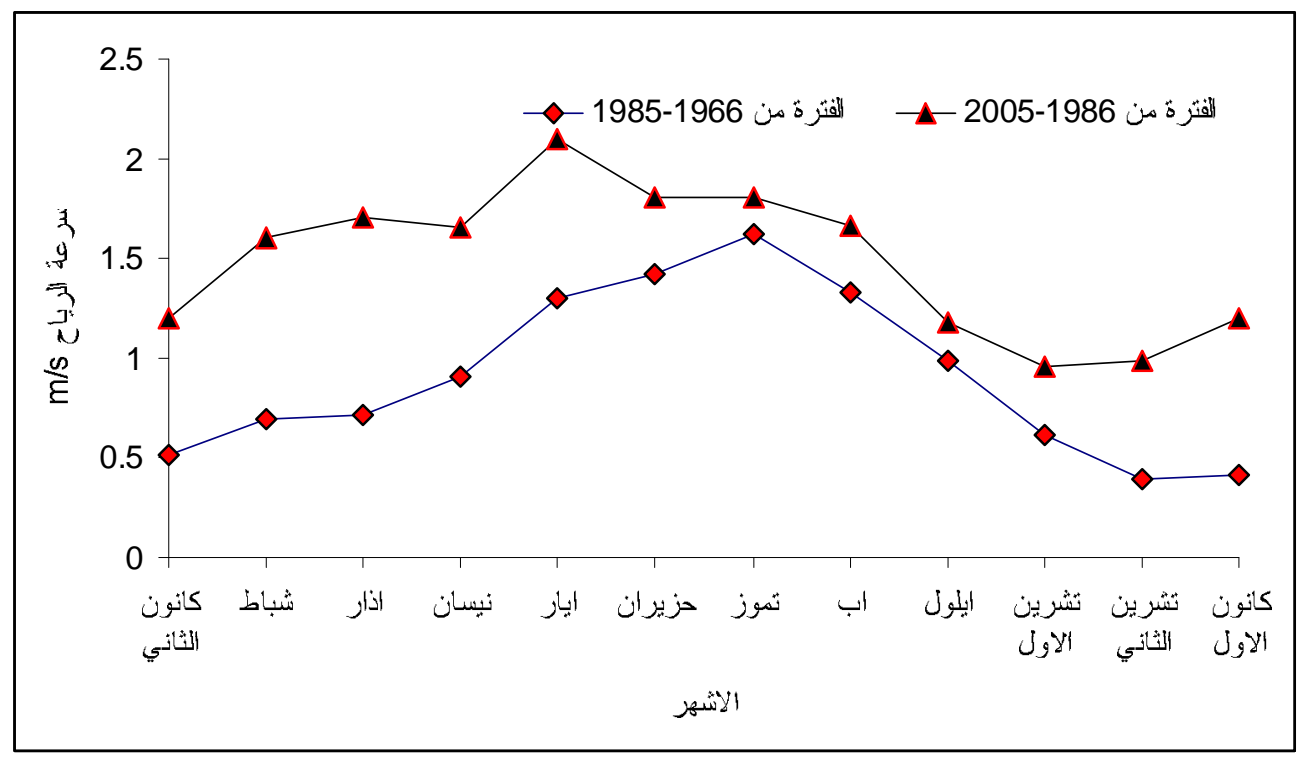

الشكل (3) يوضح المعدلات الثشرية لسرعة الرياح فبل وبعد انثناء البحيرة

2 - دراسة العلاقة بين عنصر الموازنة المائية الداخل وهو الامطار اللى عنصر الموازنة المائية الخارج وهو التبخـر

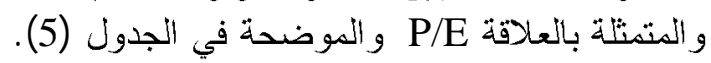

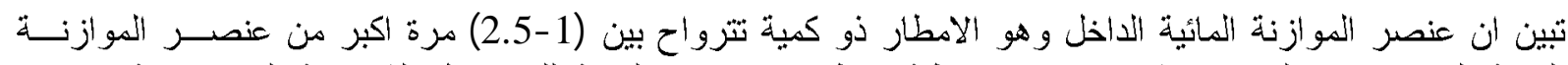

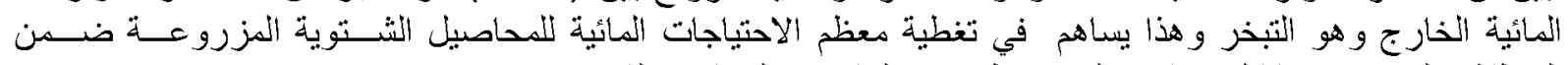

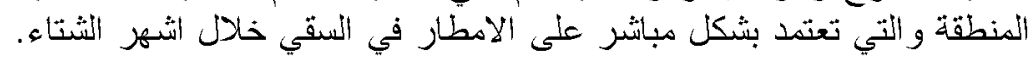

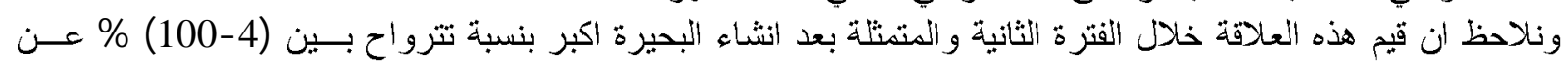

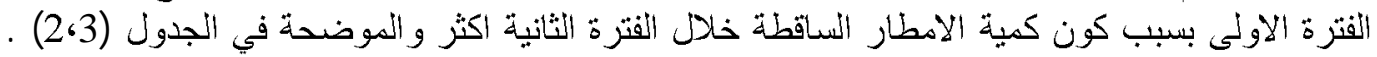

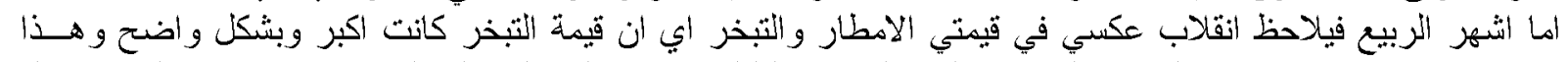

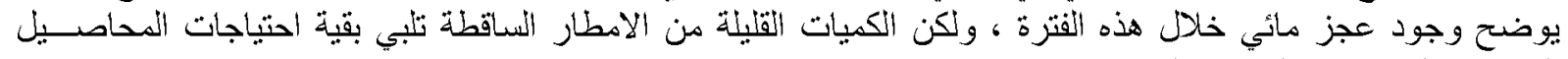

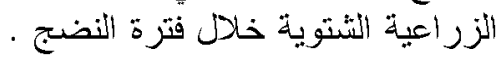

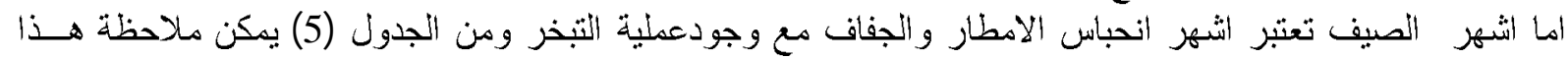

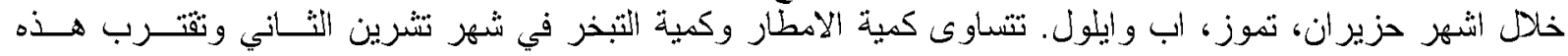

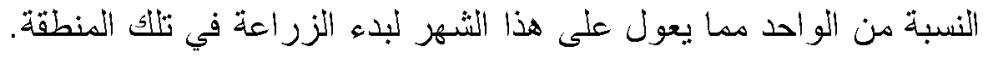

الجدول (5) يوضح المعدلات الثهرية للعلاقة P/E للفترتين قبل وبعد انشاء البحيرة

\begin{tabular}{|c|c|c|c|c|c|c|c|c|c|c|c|c|}
\hline كانون & تنثرين & تالاورين & اينول & اب & تموز & حزيران & اياز & نيسان & الثار & شباط & كانتون & الاشهر \\
\hline 2.32 & 0.933 & 0.087 & 0.005 & $\mathbf{0}$ & 0 & 0 & 0.06 & 0.31 & 0.713 & 1.35 & 2.22 & 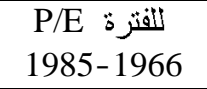 \\
\hline 2.59 & 0.97 & 0.12 & 0 & 0 & 0 & 0.0093 & 0.086 & 0.33 & 0.883 & 1.65 & 2.3 & $\begin{array}{c}\text { P/E للفنزة } 1986 \\
\text { 2005- }\end{array}$ \\
\hline 10.42 & 3.81 & 27.5 & 100 & O & 0 & 100 & 30.23 & 6.06 & 1925 & 18.18 & 3.48 & الثنانية التي الاولىى \\
\hline
\end{tabular}

3 - تقييم العناصر المناخية للفترتين: 1 - 1التساقط المطري. 


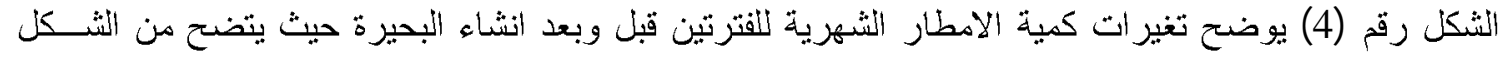

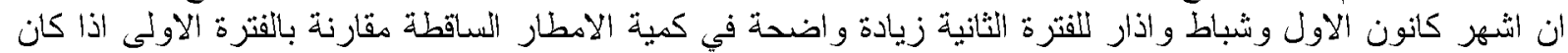

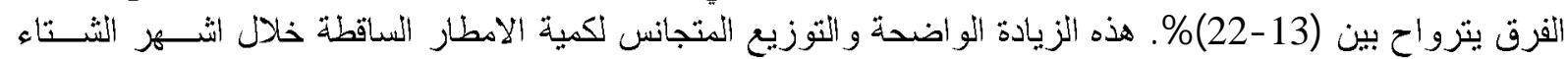

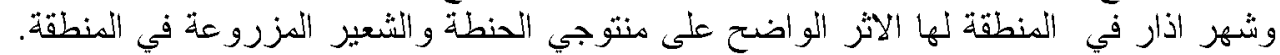
اما بقية اثشهر الربيع والخريف فلقد كان الثفرق بين القترتين في كمية الأمطار الساقطة بسيط جدا .

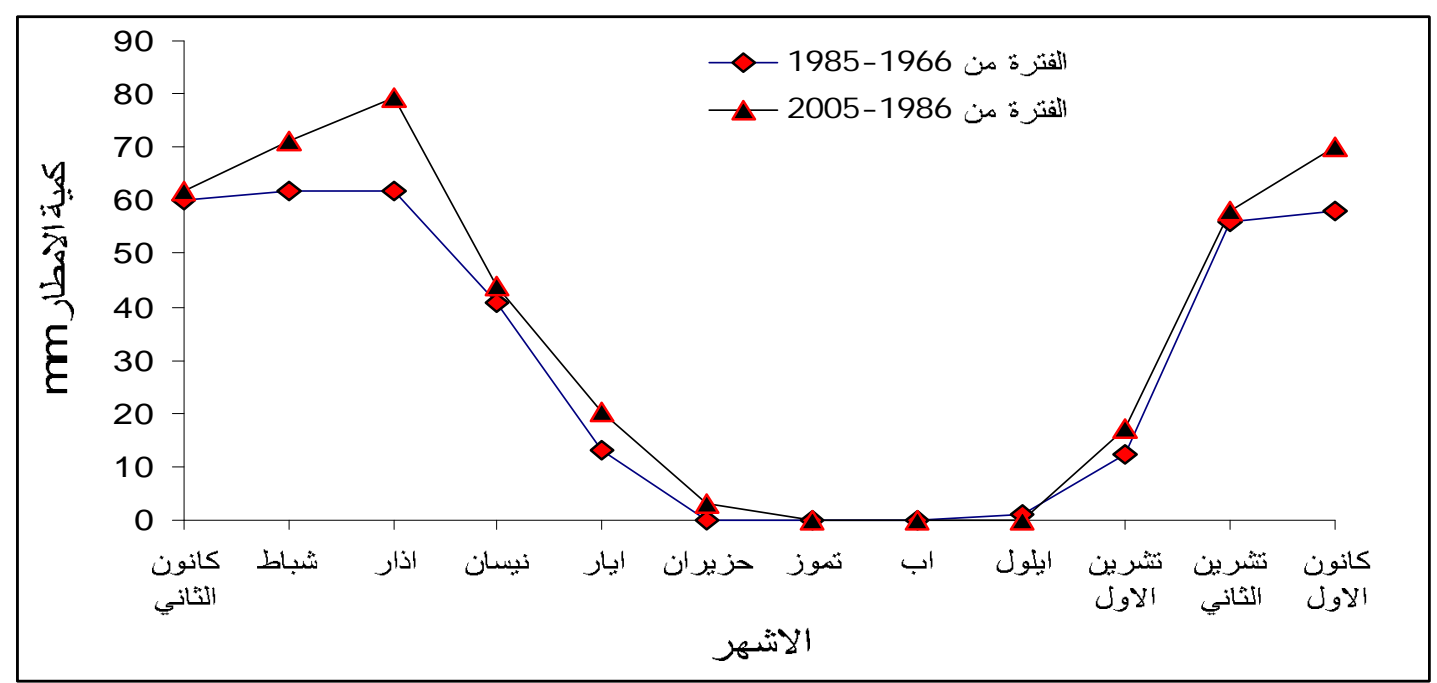

الثكل (4) يوضح المعدلات الثهرية للامطلار الساقطة قبل وبعد انشاء البحيرة

باستخدام اختبار دنكن نلاحظ وجود اختلاف معنوي في كمية الامطار الساقطة قبل وبعد انتشاء بحيرة ســـ الموصـل

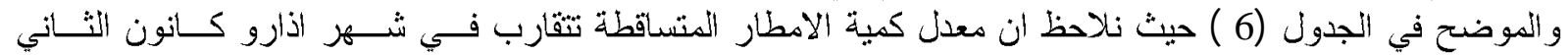

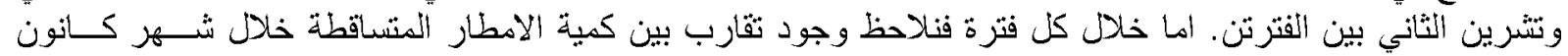

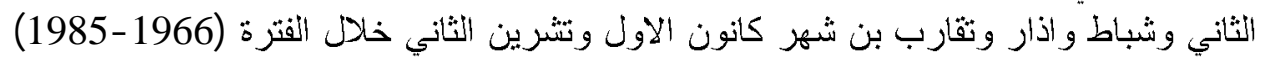
اما بالنسبة للفترة الثانية فنلاحظ اختلاف معدل كمية الامطار المتساقطة خلال كل الثهور عدان شهر شباط وكـانون باستخدام اختبار التباين نلاحظ وجود فرق معنوي بين قيم كمية الامطار المنساقطة خلال انهر السنة وبين الســنوات للفترتين قبل وبعد انثاء بحيرة سد الموصل. نلئل

جدول (6) يوضح اختبار دنكن للتساقط المطري بين الفترة قبل انثاء البحيرة وبعد انثاء البحيرة.

\begin{tabular}{|c|c|c|c|c|c|c|c|c|c|c|c|c|}
\hline كالاون & تثثرين & تشثرين & ائول & اب & تموز & حزيران & اليار & تيسان & اذذار & شباط & كانثاني & الاشهره \\
\hline 58 & 56 & 12.3 & 1.2 & 0 & 0 & $\overline{0}$ & 13.2 & 41 & 62 & $\overline{61.9}$ & 60 & قُبل أنثاء \\
\hline bc & c & e & f & $\mathbf{g}$ & $\mathbf{g}$ & g & e & d & $\mathbf{a}$ & $\mathbf{a}$ & ab & (1965) البحير (1985) - \\
\hline 70 & 58 & 17.1 & (0 & 0 & $\mathbf{0}$ & 3.1 & 20.3 & 44 & 79.5 & 71 & 62 & بعل ا(نتشاء \\
\hline b & c & f & h & h & h & g & f & e & $\mathbf{a}$ & b & c & البحير (2005) \\
\hline
\end{tabular}

p>0.05 الاحرف المختلفة تعني وجود فرق معنوي بالاتجاه الافقي و العمودي عند فيمة دلالة abcdefgh

2 


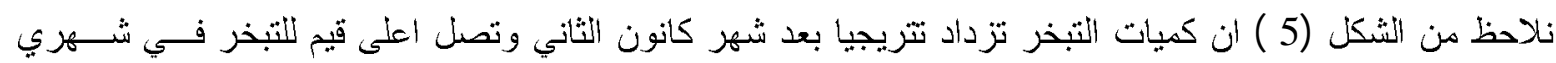

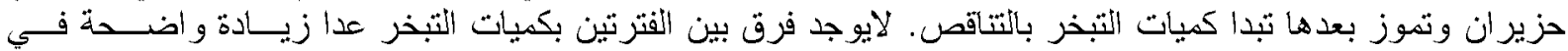

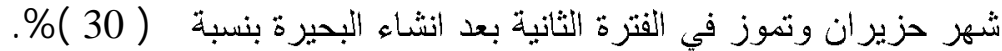

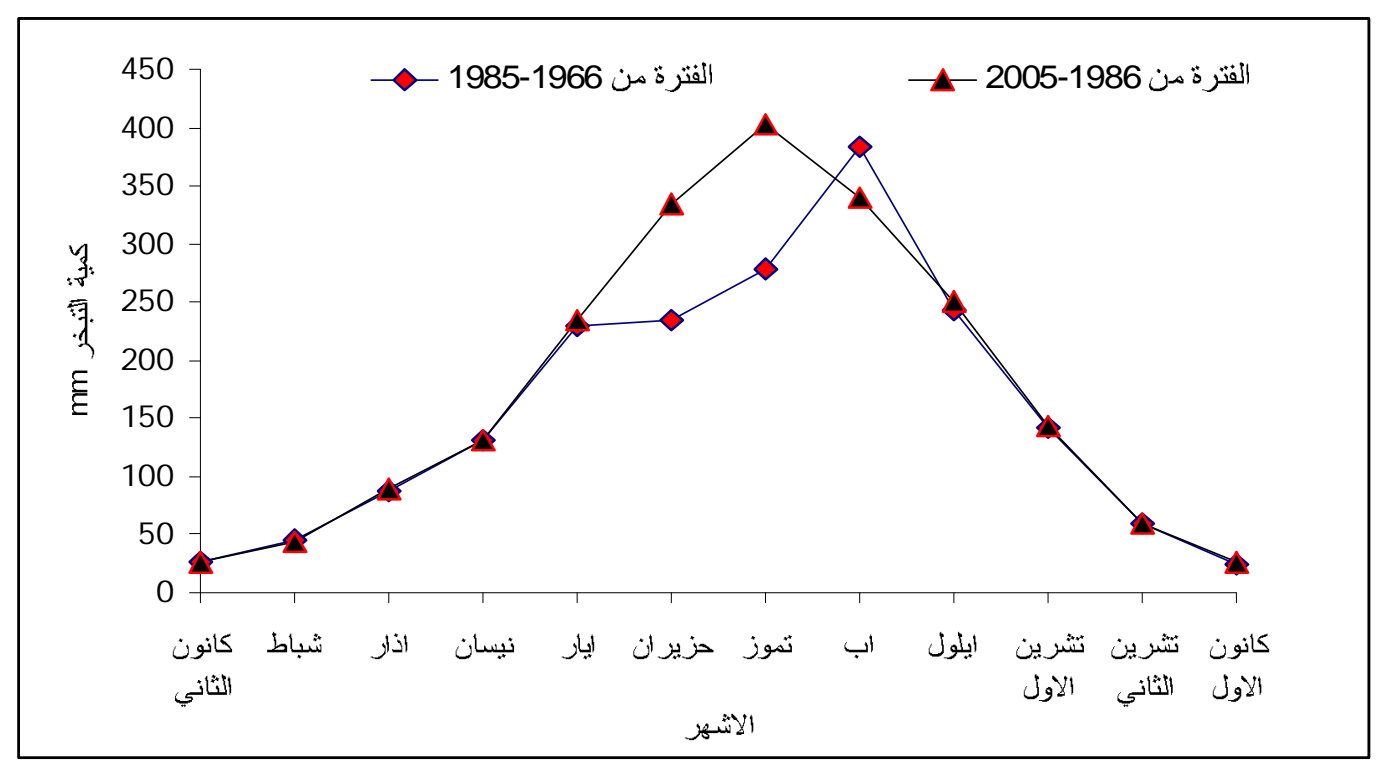

الشكل (5) يوضح المعدلات الثهرية للتبخر قبل وبعد انثاء البحيرة

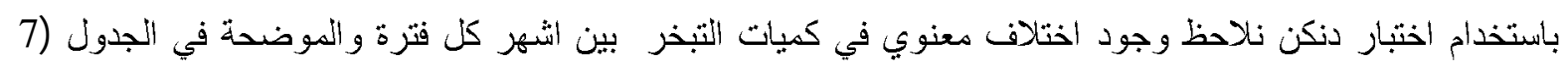

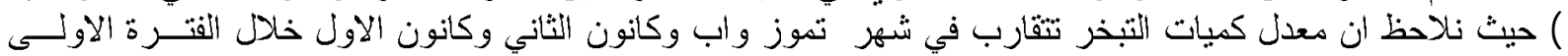

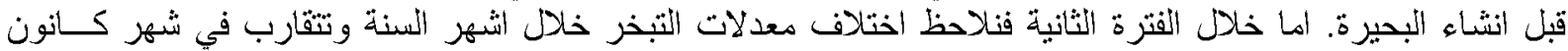

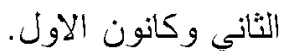

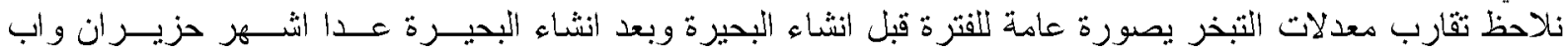
و ايلول. باستخدام اختبار الثباين نلاحظ وجود فرق معنوي بين قيم كميات التبخر خلال اشهر السنة وبين السنوات للفترتين قبـلـل

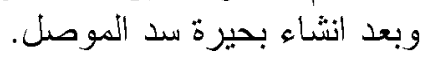

جدول (7) يوضح اختبار دنكن للتبخر بين الفترة قبل انشاء البحيرة وبعد انثاء البحيرة

\begin{tabular}{|c|c|c|c|c|c|c|c|c|c|c|c|c|}
\hline كالنون & تنشيرين & نشرين & ايلون & اب & تموز & حزيران & اياز & نيسان & أذار & شباط & كانوني & الالشهر \\
\hline 25 & 60 & 141 & 244 & 384 & 279 & 235 & 229 & 131 & 87 & 46 & 27 & قبل انثاء \\
\hline $\mathrm{j}$ & $\mathrm{h}$ & e & b & $\mathrm{a}$ & $\mathrm{a}$ & $\mathrm{c}$ & d & $\mathrm{f}$ & $\mathrm{g}$ & $\mathrm{i}$ & $\mathrm{j}$ & البحيرة(1985) \\
\hline 27 & 60 & 143 & 250 & 339 & 402 & 335 & 235 & 132 & 90 & 43 & 27 & بعذ انثاء \\
\hline $\mathrm{j}$ & $\mathrm{h}$ & $\mathrm{e}$ & c & b & $\mathrm{a}$ & b & d & f & $\mathrm{g}$ & $\mathrm{i}$ & $\mathrm{j}$ & البحيزة(2005) \\
\hline
\end{tabular}

p<0.05 الاحرف المختلفة تعني وجود فرق معنوي بالاتجاه الأفقي و العمودي عند قيمة دلالة

3 - سرعة الرياح و اتجاهها

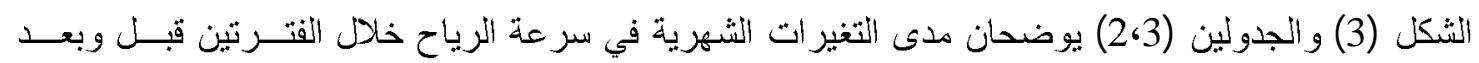

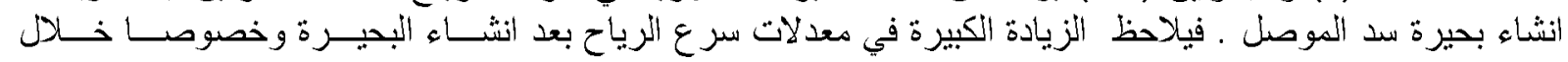




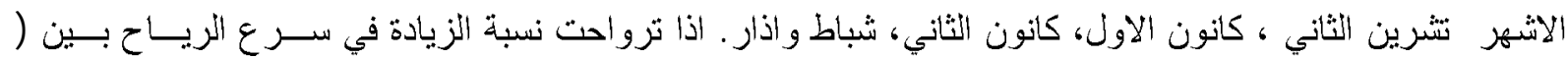

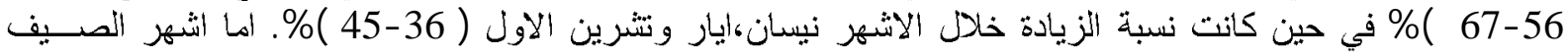

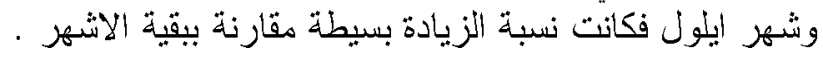

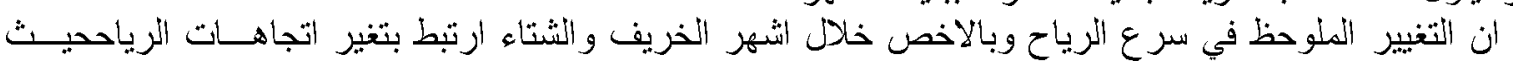

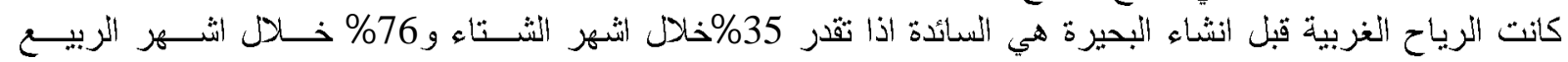

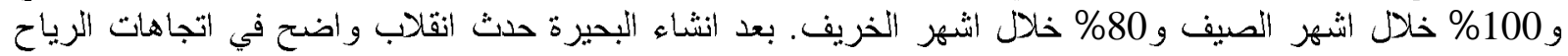

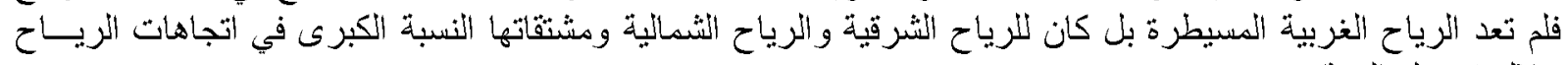
خلال فصول اللسنة.

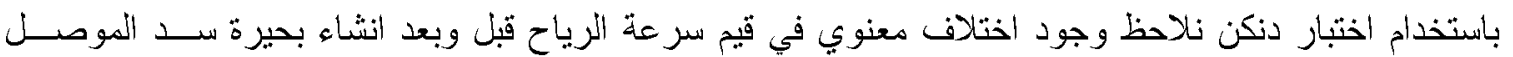

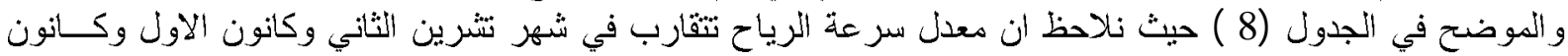
الثاني خلال الكترة قبل انتشاء البحيرة.

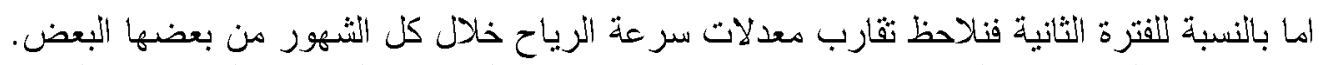

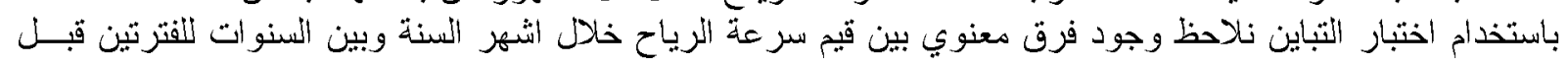
وبعد انثاء بحيرة سد الموصل.

جدول (8) يوضح اختبار دنكن لقيم سرعة الزرياح بين القترة قبل انثاء البحيرة وبعد انثاء البحيرة

\begin{tabular}{|c|c|c|c|c|c|c|c|c|c|c|c|c|}
\hline كانون & الثناني & تلاون ين & ايلون & اب & تموز & حزير ان & ايار & نيسان & اذذار & شباط & كانثون & الاشهر \\
\hline $\begin{array}{c}0.41 \\
\mathrm{f}\end{array}$ & $\begin{array}{c}0.39 \\
\mathrm{f}\end{array}$ & $\begin{array}{c}0.61 \\
\text { ef }\end{array}$ & $\begin{array}{c}0.99 \\
\text { cd }\end{array}$ & $\begin{array}{c}1.33 \\
\mathrm{~b}\end{array}$ & $\begin{array}{c}1.62 \\
a b\end{array}$ & $\begin{array}{c}1.42 \\
\mathrm{ab}\end{array}$ & $\begin{array}{l}1.3 \\
b c\end{array}$ & $\begin{array}{c}0.91 \\
\text { de }\end{array}$ & $\begin{array}{c}0.72 \\
\text { def }\end{array}$ & $\begin{array}{c}0.7 \\
\text { ef }\end{array}$ & $\begin{array}{c}0.51 \\
\mathrm{f}\end{array}$ & البحيرة: أبنل انثاء 1966 - 1985 \\
\hline $\begin{array}{c}1.2 \\
\mathrm{e}\end{array}$ & $\begin{array}{c}0.99 \\
\mathrm{f}\end{array}$ & $\begin{array}{c}0.96 \\
\mathrm{f}\end{array}$ & $\begin{array}{c}1.18 \\
\mathrm{e}\end{array}$ & $\begin{array}{c}1.66 \\
\mathrm{~cd}\end{array}$ & $\begin{array}{c}1.8 \\
\mathrm{~b}\end{array}$ & $\begin{array}{c}1.8 \\
b\end{array}$ & $\begin{array}{c}2.1 \\
\mathrm{a}\end{array}$ & $\begin{array}{c}1.65 \\
\text { cd }\end{array}$ & $\begin{array}{c}1.7 \\
\mathrm{c}\end{array}$ & $\begin{array}{c}1.6 \\
d\end{array}$ & $\begin{array}{c}1.2 \\
\mathrm{e}\end{array}$ & البحيرة (2005) \\
\hline
\end{tabular}

p>0.05 الاحرف المختلفة تعني وجود فرق معنوي بالاتجاه الأفقي و العمودي عند قيمة دلائة

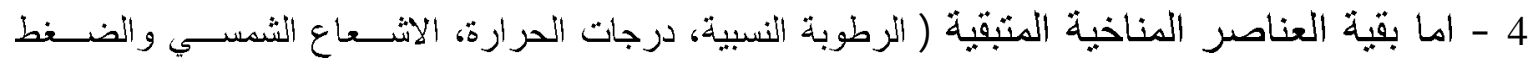

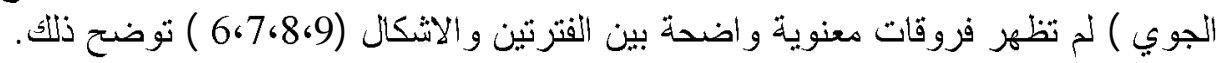

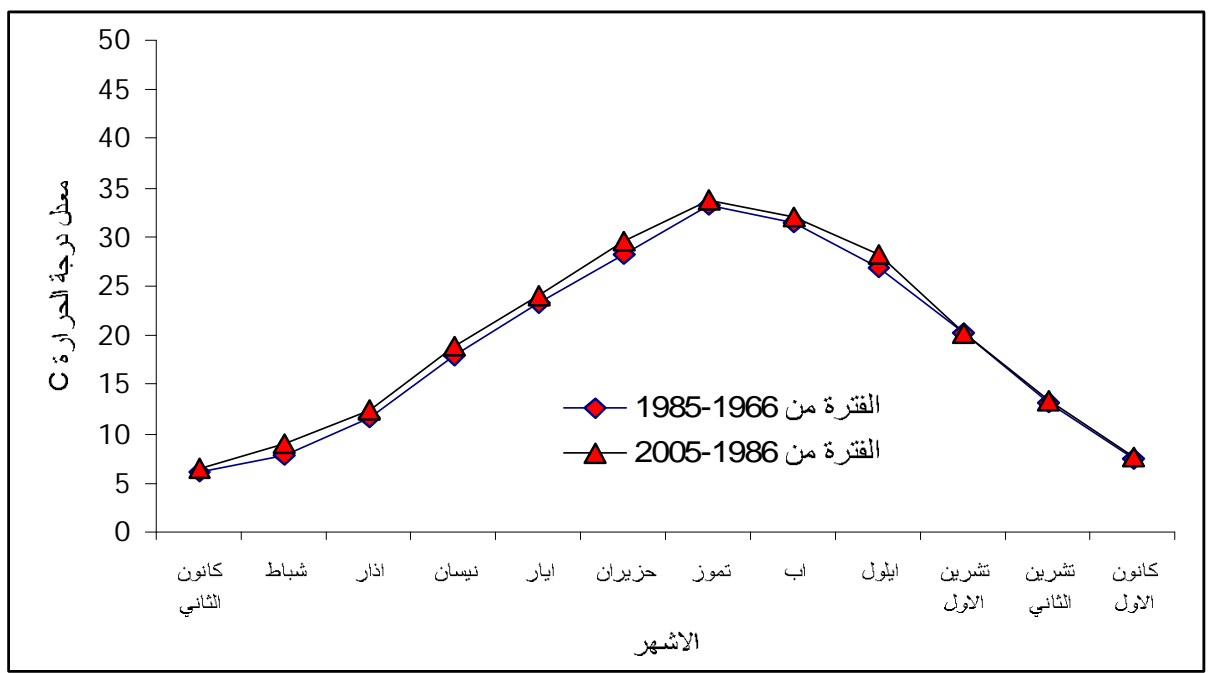


الشكل (6) يوضح المعدلات الثهرية لدرجات الحر ارة قبل وبعد انشاء البحيرة

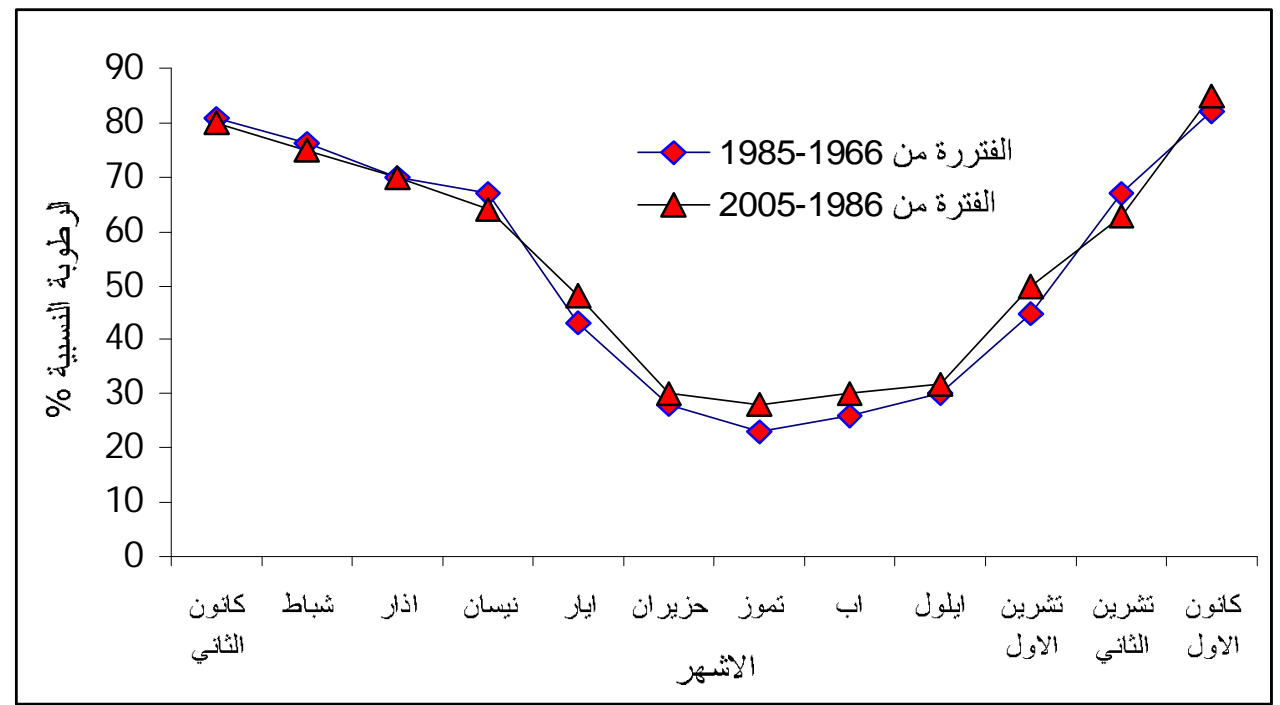

الثكل (7) يوضح المعدلات النهرية للرطوبة النسبية قبل وبعد انشاء البحيرة

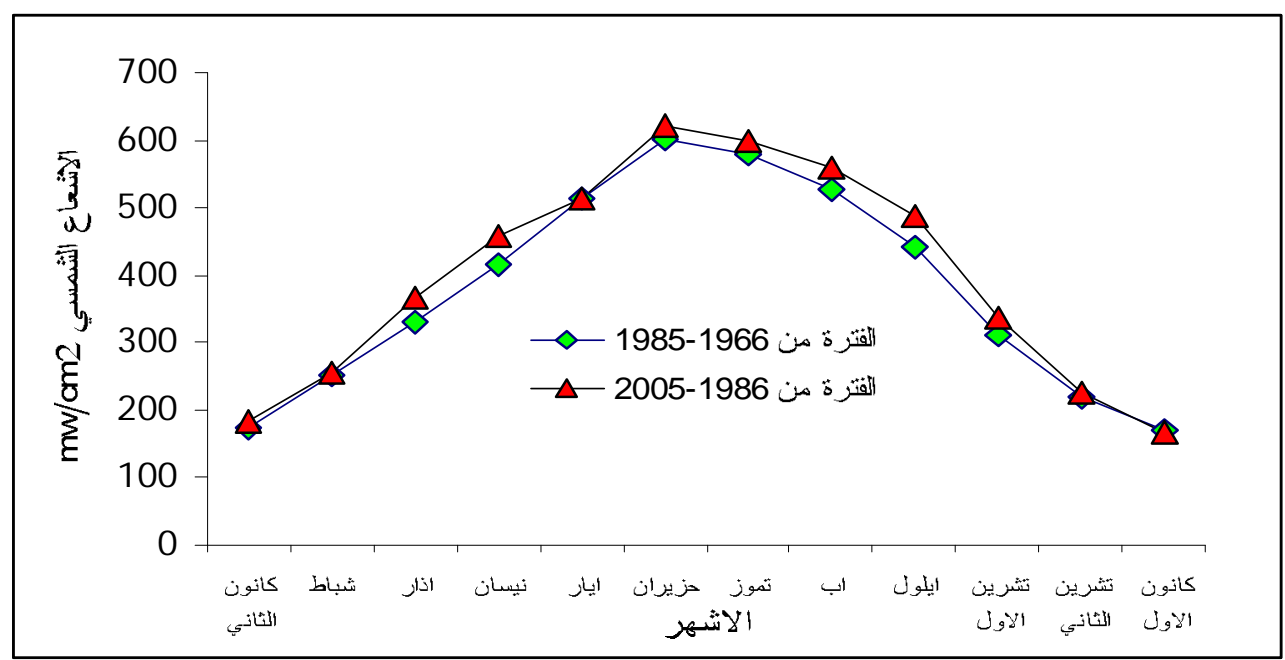

الثكل (8) يوضح المعدلات الثشهرية للاشعاع الثشسي قبل وبعد انثاء البحيرة

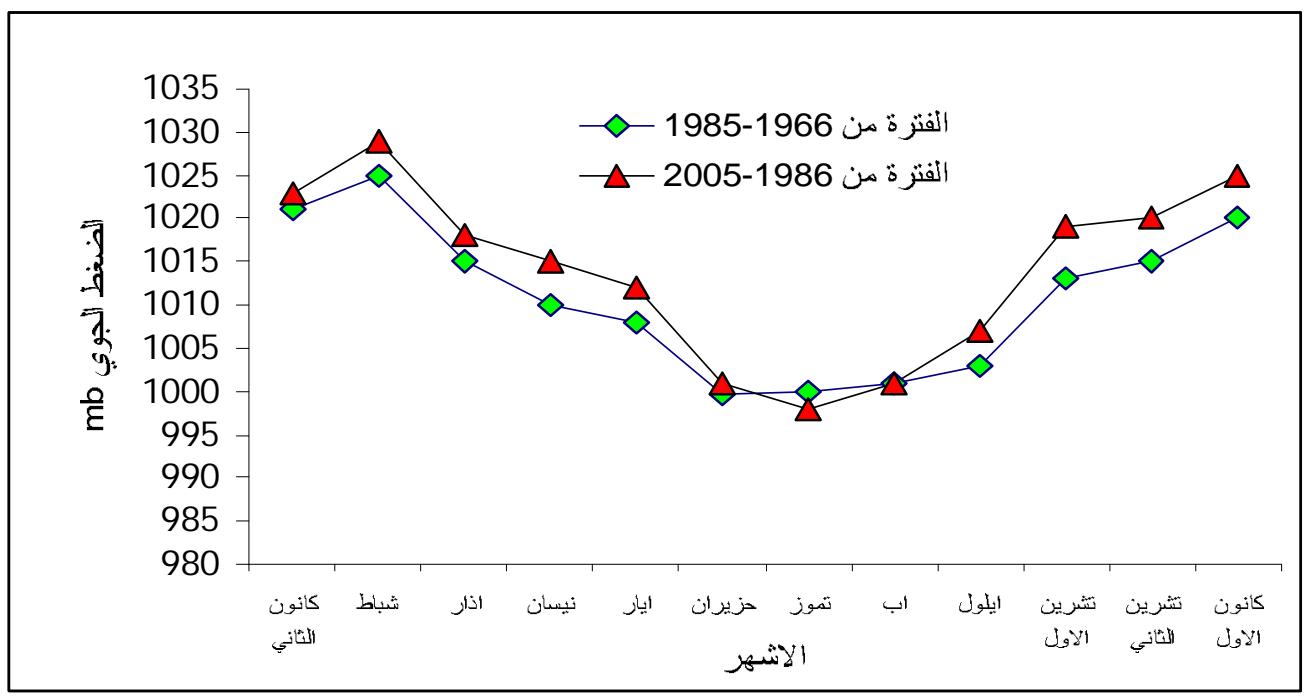


الشكل (9) يوضح المعدلات الثهرية للضغط الجوي قبل وبعد انثاء البحيرة

ألاستنتاجات

1 - وجود زيادة في قدرة التبر يد للفترة الثانية على الاولى بنسبة تترواح من ( 5 -24 ) هو في غالبية شهور النسنة

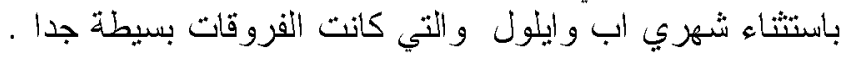
2 - اظهرت أشهر الثتاء زيادة واضحة في قيمة P/E مقارنة بالاشهر الاخرى التي تنخفض فيها هذه النسبة الى ان تصل الى الصفر في اشهر الصيف. 3 - صنفت اربعة حالات لطبيعة جو مدينة الموصل اعتمادا على الاحساس التشري تبعا للفئات المختلفة من قدرة

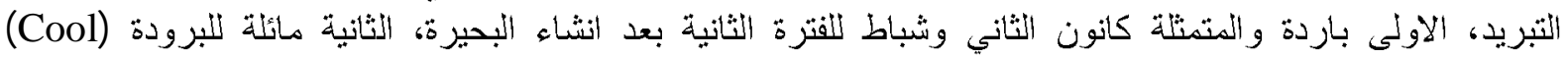

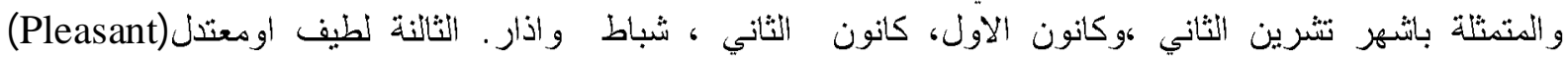

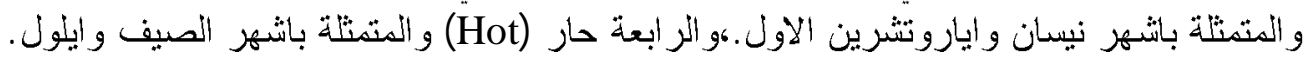

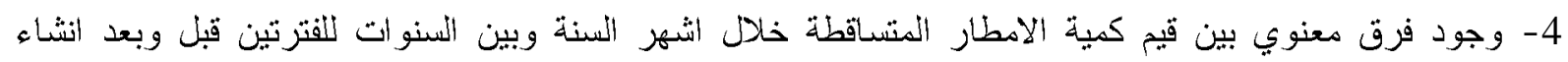
بحيرة سد الموصل. 5 - نلاحظ تقارب معدلات التبخر يصورة عامة للفترة قبل انشاء البحيرة وبعد انثناء البحيرة عدا اثنهر حزيران واب و ايلول. 6 - حدوث زيادة كبيرة في معدلات سرعة الرياح بعد انثاء البحيرة في معظم اشهر السنة ـ كما حصل تغير واضح

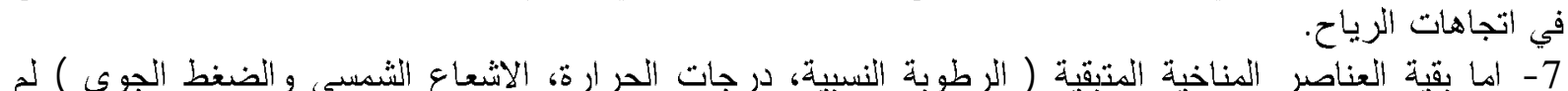

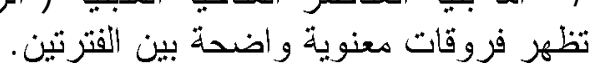

المصادر

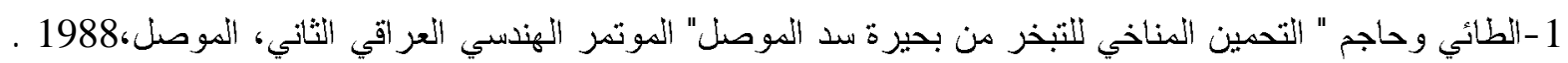
2 -الطائي وسليمان " المو ازنة المائية الاولية لبحيرة سد الموصل " ، مركز بحوث سد الموصل، جامعة الموصل،1989

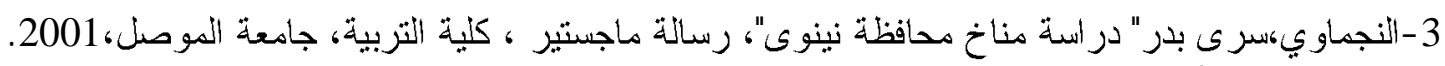

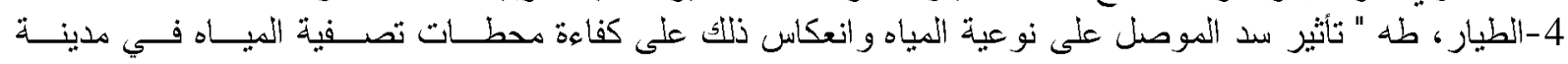

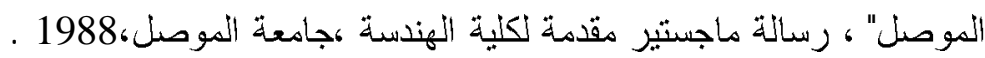

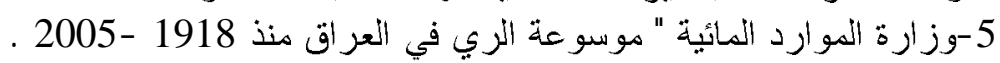

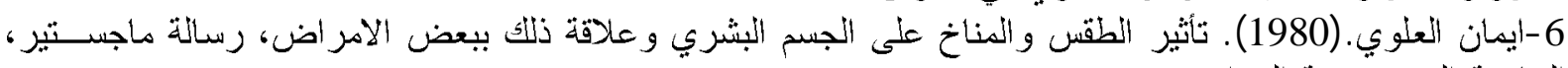

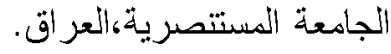

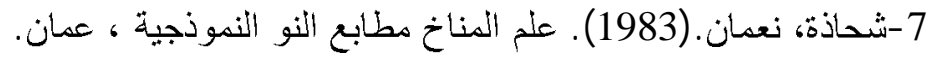

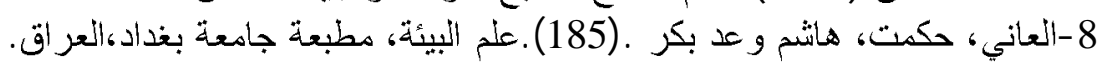

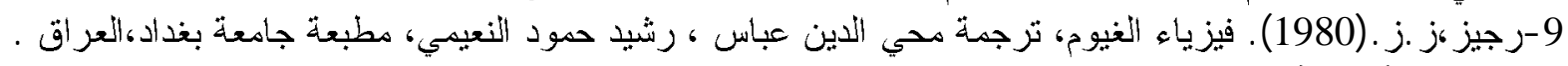

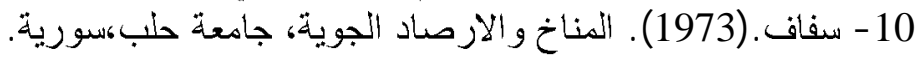

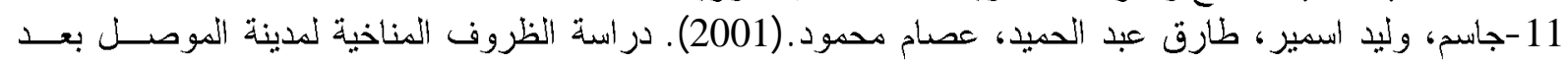

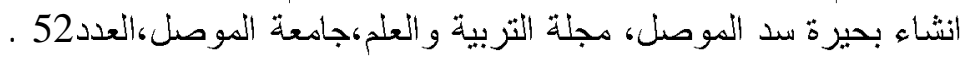
12-Cena, M., Gregorezuk, M. and Wojcik,G. (1966).An attempt of formula determination for computation of biometeorological cooling power in Poland, Roezniki Nauk Rolnizych, 119D, pp442-446.

13- Landsberg, H.E. (1972). The assessments of human bioclimate ,Alimited review of physical parameters, WMO-Geneva- Switzerland, No.331.

تم اجراء البحث في كلية الهندسة - جامعة الموصل 